\title{
In Stent Restenosis
}

National Cancer Institute

\section{Source}

National Cancer Institute. In Stent Restenosis. NCI Thesaurus. Code C100081.

Fifty percent or greater stenosis within an existing stent. (ACC) 